\title{
Problems of introduction information about the limits of administrative and territorial units
}

\author{
Denis Avdeev ${ }^{1 *}$, and Alexander Kryakhtunov ${ }^{1}$ \\ ${ }^{1}$ Industrial University, Department of Geodesy and Cadastral Activities, 625000, Building 2, \\ Lunacharskogo St., Tyumen, Russia
}

\begin{abstract}
This work is devoted to the issues of entering into the Unified State Register of Real Estate (hereinafter referred to as USRN) information about the location of borders between subjects of the Russian Federation, borders of municipalities, and settlements on the example of the Tyumen region. The procedure and features of the establishment, change of administrative-territorial division are considered. Analysed the legal aspects and grounds for carrying out activities for the coordinate description of administrative boundaries as objects of land management. At the same time, problems that arise both at the stage of adoption of regulatory acts establishing administrative boundaries and at the stage of preparation and coordination of land management documentation are identified and justified. According to the results of the work, a number of proposals were formulated, which will allow to provide the USRN with information on the administrative-territorial division in full.
\end{abstract}

\section{Introduction}

Currently, within the framework of the investment policy pursued in order to increase the attractiveness of the region in the Tyumen region, much attention is paid to the development of urban planning. So back in 2010, the Tyumen region became the first entity in the Russian Federation, which approved in full the entire list of urban planning documentation. Currently, systematic work is being carried out on an ongoing basis to amend the town planning documentation in order to bring it in line with the requirements of the changing legislation. At the same time, the territory planning documentation sector is actively developing, over 2018 more than 400 planning and surveying projects have been approved. The city of Tyumen is the only city whose territory is fully provided with land surveying projects. By means of which, the procedure for granting land plots is transparent and predictable, and the development of the city is streamlined in strict accordance with the master plan. Including the sustainable development of urbanized areas is impossible without digitalization of urban planning activities. On the territory of the region for more than 10 years one of the best in Russia State Information System for providing town-

${ }^{*}$ Corresponding author: $\underline{\text { AvdeevDA@,72to.ru }}$ 
planning activity has been operating, in which the entire history of the life cycle of objects is conducted, from their design status to removal from the register [1].

At the same time, work is carried out on the preparation and submission to the Unified State Register of Real Estate of information (hereinafter - USRN) about the boundaries of municipalities, settlements, land use and development rules. In connection with the adoption of a comprehensive plan of activities, as well as the approval of federal and regional target models for increasing investment attractiveness, the deadlines and stages for entering information are regulated and established. The urgency of the USRN filling is in the availability of vector and semantic data in the process of managing territories, as well as providing owners and interested persons about land use regimes, current regulations and restrictions.

The procedure and deadlines for entering information are established and regulated by Federal Law No. 218 "On State Registration of Real Estate", the Town Planning Code of the Russian Federation, Federal Law No. 78 "On Land Management", and other regulatory legal acts. In accordance with which the boundaries between the subjects of the Russian Federation and the boundaries of municipalities are objects of land management. For documents describing their location, it is planned to conduct a land management expertise and to include in the State Fund data obtained as a result of land management, which is carried out by the territorial agency of the Federal Register. The exception since 2019 was the transfer of authority to conduct an examination to the federal agency of the Federal Registration Service for documents describing the boundaries between the subjects of the Russian Federation. In this connection, the time has increased from 1 to 3 months .

In 2018, the boundaries of settlements and the boundaries of territorial zones were excluded from the composition of land management facilities, which accelerated and simplified the procedure for entering into the USRN, as well as changed the requirements for the composition of documents describing the location. At the same time, the innovation made it mandatory to attach a coordinate description of the boundaries of populated areas and territorial zones to territorial planning and urban zoning documents, and obliged local governments to send such documents within five days from the time to the registration authority [2].

Thus, over several years of active work in the Tyumen region, it was possible to achieve a significant filling of the registry with information on the boundaries of administrativeterritorial entities.

\section{Materials and methods}

The territory of the Tyumen region is within the administrative boundaries established by the Decree of the Presidium of the Supreme Soviet of the USSR of August 14, 1944; the region includes the territories of the Khanty-Mansiysk Autonomous Okrug - Ugra and the Yamalo-Nenets Autonomous Okrug, which are independent subjects of the Russian Federation.

The administrative-territorial structure of the Tyumen region is defined by the Law of the Tyumen region of November 4, 1996 No. 53, its principle is the division of the territory into municipal formations, of which 21 municipal districts and 5 urban districts. In turn, the territories of municipal districts include the territories of urban and rural settlements, with their populated areas.

The location of the boundaries of municipalities is established by the Law of the Tyumen Region of 05.11.2004 No. 263 "On the Establishment of the Borders of the Municipalities of the Tyumen Region and Empowering them with the Status of a Municipal District, Urban District and Rural Settlement" (hereinafter - Law No. 263) by text describing turning points with defining the length on identified topographic objects, taking 
into account materials of land management, forest management and materials of coordination of regional boundaries [3].

In accordance with the order of the Ministry of Economic Development of Russia of 03.06.2011 No. 267 "On Approval of the Procedure for Describing the Location of Land Management Object Borders", administrative borders should not cross the borders of land plots, information about which are contained in the USRN.

However, when comparing the data contained in the USRN and the limits established in accordance with Law 263, rough intersections are revealed, which cannot be eliminated without violating the textual description. Thus, the implementation of land management work is impossible without amending Act No. 263.

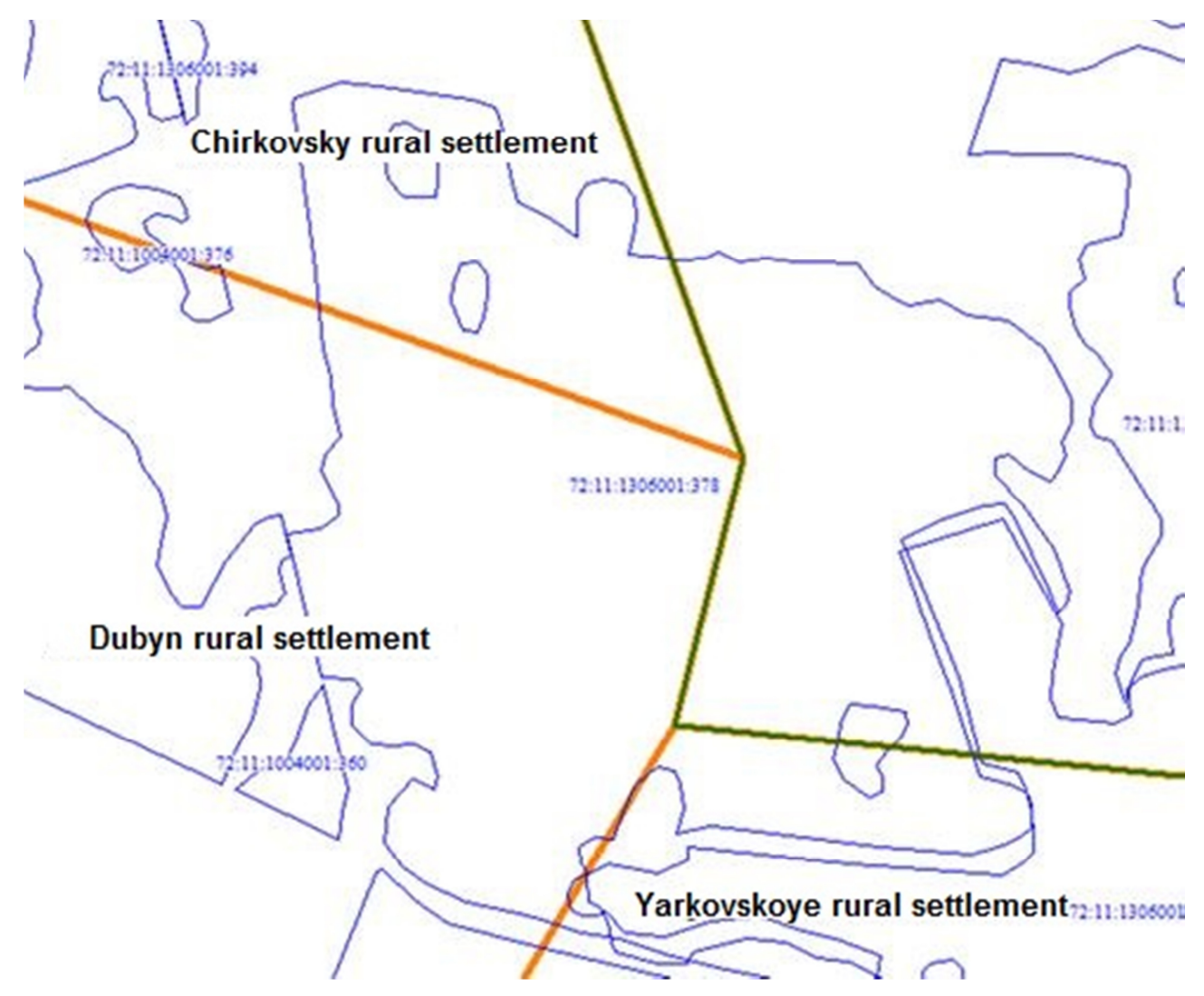

Fig. 1. Crossing the boundaries of land by the boundaries of municipalities.

The procedure for establishing or changing the boundaries of the territories of administrative-territorial entities is established by the Law of the Tyumen Region of November 4, 1996 No. 53, this issue is within the competence of the Tyumen Regional Duma. The procedure for changing the boundaries is time consuming and requires the preparation of an impressive package of documents. In preparing the draft law, the opinion of the population is taken into account, a financial and economic assessment is calculated, the necessary cartographic material is being prepared.

After the amendment of Law 263 and bringing the boundaries of administrativeterritorial entities in line with the requirement of cadastral registration, a map (plan) for the location description is prepared again. After this, land management documentation is to be included in the fund of data obtained as a result of land management, on the basis of a 
positive conclusion of state expertise. The state expertise of land management documentation is carried out by a territorial body of the Federal Service for State Registration, Cadastre and Cartography; the period for conducting an expertise is limited by internal regulations and is 30 days [4].

Thus, since the detection of overlaps until the preparation of the coordinate description of administrative boundaries, a long period of time passes, which cannot be shortened. During this time, the real estate registry continuously continues to be updated with information, new plots are formed, existing ones are refined, as a result of which intersections are revealed again. Entering information in the Register on the location of the boundaries of administrative-territorial entities becomes impossible, and the usefulness of work on changing borders is equal to zero.

At the same time, until now, a large number of land plots have been included in the Register, information about which is contained declaratively, that is, without coordinates of borders.

Clarification of the boundaries of land is made in accordance with the cartographic material and title document. According to the requirements of part 11 of article 22 of the Federal Law No. 218-FZ dated July 13, 2015 "On State Registration of Real Estate", the boundaries of the land plot shall not cross the boundaries of the municipality, the boundaries of the settlement, except for the case if the error reproduced in the Unified State Register of Real Estate determining the location of the boundaries of such a municipality in the document on the basis of which information was entered into the USRN. Thus, there is no possibility to clarify the boundaries of land $x$ plots, the rights to which arose prior to the establishment of the boundaries of municipalities by the law.

Based on the above, we can conclude that there is a need for additional legal regulation of the problem. A solution to this situation could be amending the legislation, which will clarify the boundaries of land plots, the rights to which arose before the EDRN introduced information on the boundaries of municipalities, and entered the EDR with the existing intersections, provided that such an intersection will not prevent the use of land in accordance with its intended purpose.

The main problem that impedes the immediate registration of the USRN with information about the boundaries of settlements and territorial zones is the initial need to bring the territorial planning documents in accordance with the changed urban planning legislation. Currently, the administrations of the municipalities of the Tyumen region are carrying out large-scale work on introducing changes to the master plans and rules for land use and development. Within the framework of the concluded municipal contracts, preparation of materials is provided for entering information into the USRN within the boundaries of settlements and territorial zones. As of the May of 2019, 84\% of information about the boundaries of settlements and $45 \%$ of information about the boundaries of settlements and territorial zones has been entered into the USRN.

At the stage of preparation of territorial planning and urban zoning documents, problems arise with land plots that are occupied by linear objects, land plots that have several circuits in their composition. In addition, during the lengthy procedure for agreeing on and approving town planning documentation, the boundaries of land plots that were not previously displayed on the cadastral plan of the territory often become clearer. For such cases, Law No. 280-FZ amended the Law "On State Registration of Real Estate", which allows the registration authority to make changes to the register of borders in the event that land borders and residential areas (territorial zones) are detected as part of the procedure for entering information about boundaries in usrn. The above rule is applicable when the location of such a land plot in a populated area and territorial zone is $75 \%$ of the area and more. 
Thus, there is a precedent for discrepancies between the information of the USRN and the town planning documentation, which in turn becomes a problem for the owners of land plots when they receive a city planning plan for the memory or permission (notification) for construction. As the above documents in accordance with the Urban Planning Code are prepared on the basis of the master plan and the Land Use Rules for development. An equally interesting problem is the absence of the possibility to indicate in the XMLdocument a complete list of the existing town-planning regulations provided for by the Land Use Rules for Development, as well as the ability to display semantic data in the cadastral plan of the territory [5].

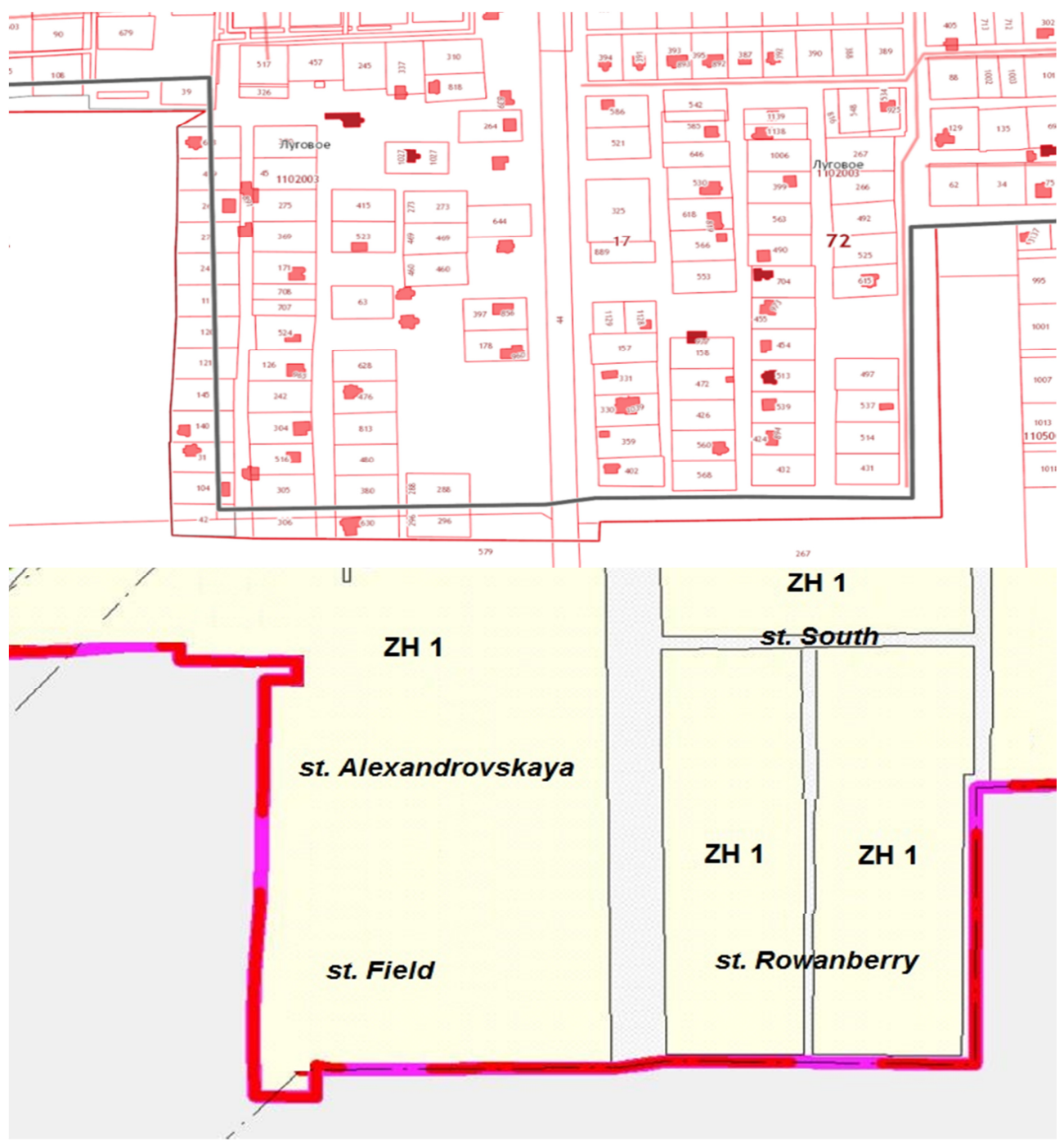

Fig. 2. Example of discrepancy between the USRN and urban planning documentation. 
In order to solve the problems of the above problems, I have formulated a number of proposals, namely:

- In order to make information about the boundaries of municipalities, provide for the possibility of admissibility of border crossings of municipalities (with the exception of the boundaries of settlements) of land (all categories of land except for lands of settlements). At the same time, I propose to leave the norm of inadmissibility of crossing the borders of municipal formations formed by land plots without changes;

- In order to respect the rights of citizens, improve the investment climate, increase the efficiency of land use, I consider it necessary to supplement the current legislation with the priority rules of data registered in the Register with the information provided in the order of interdepartmental information interaction and determination that "the information on the boundaries of the settlement contained in the USRN. Including to establish that the map of the boundaries of the settlement, as well as the map of the town planning zoning as part of the rules of land use and development and information about the boundaries of the territorial zone act in a part that does not contradict the information on such boundaries (parts of the boundaries) contained in the Register.

At the same time, a simplified procedure should be introduced in order to bring the map of the boundaries of a settlement, and the map of town planning zoning into compliance with the information of the Register, without conducting a public discussion procedure.

Adjustment of legislation will have a positive impact on the development of the construction industry without the establishment of additional administrative barriers that may affect the extension of the construction period.

\section{Discussions}

Thus, my proposals in part of the boundaries of municipalities will allow you to perform target models, however, in a single coordinate space will contain reliable information about the administrative division. Thus, the territories will be demarcated between the municipalities and the subjects of the Russian Federation, which will make it possible to form plots, based on the existing coordinate description, and also to use the territories rationally and effectively. However, the admissibility of crossing the borders of municipalities with the borders of land plots will add a new problem, which is the difficulty of assigning addresses, and determining the budget of the land rent recipient. In this case, it is possible to consider a certain transitional period, before the Register is fully filled with information about land plots, when addresses and a beneficiary will be determined by the highest percentage of such a land plot in a particular municipality. Of course, in the future, when the Register will be filled with information about land plots, it will be necessary to make changes to the descriptive part of Law 263 and to adjust the administrative boundaries, but this procedure will be final.

In terms of simplifying the procedure of bringing the town-planning documentation in accordance with the information of the Register, on the boundaries of settlements and territorial zones, my proposals will allow landowners without additional procedures to obtain a town-planning plan and building permit without intersections. Thus, the mechanism that the legislator provided for in Federal Law 507 will work in full. As currently, the initiative embodied in it has not been implemented. In my opinion, this addition will have only positive results. 


\section{Conclusions}

Summing up the above, it should be concluded that the order of filling the Register with information about the boundaries between the subjects of the Russian Federation, the boundaries of municipalities and settlements has been established in detail. All procedures are regulated; the timing of the transfer of information and the deadline for immediate submission is limited, which allows you to quickly achieve results. At the same time, problems that arise in practice, and create a mutual barrier for local governments, as well as for owners and land users have been identified. To solve such problems, additional legislative regulation, amending a number of federal laws and additional methodological support are required. The proposals I have formulated will make it possible to close legislative gaps, which will exclude a number of barriers to the use and disposal of land plots in full, as well as generally increase the investment attractiveness of the regions.

\section{References}

1. T.V. Ilyushin, Proc. univer. Surv aer. phot., 3, 84-95 (2013)

2. V. Vasiliev, Y. Sci., 14, 62-66 (2016)

3. O. Zakabluk, Sci. Jour. "Stud. Forum", 13 (3) (2017)

4. A.I. Golovanov, Environmental engineering: a textbook for university, 552 (2008)

5. Yu. G Korukhov, Forensic examination in civil proceedings, 15 (2016) 